\title{
Safety and efficacy of self-expanding metal stents for biliary drainage in patients receiving neoadjuvant therapy for pancreatic cancer
}

\section{(ㄷ)(i) $\odot$}

\author{
Authors \\ Darren D. Ballard, Syed Rahman, Brian Ginnebaugh, Abdul Khan, Kulwinder S. Dua
}

Institution

Division of Gastroenterology and Hepatology, Medical

College of Wisconsin, Milwaukee, WI, U.S.A.

submitted 8.11.2017

accepted after revision 20.2.2018

\author{
Bibliography \\ DOI https://doi.org/10.1055/a-0599-6190 | \\ Endoscopy International Open 2018; 06: E714-E721 \\ (c) Georg Thieme Verlag KG Stuttgart · New York \\ ISSN 2364-3722
}

Corresponding author

Kulwinder S. Dua, MD, FRCP, FACP, FASGE, Professor of

Medicine and Pediatrics, Division of Gastroenterology and

Hepatology, Medical College of Wisconsin Milwaukee, WI

Fax: +1-414955 6815

kdua@mcw.edu

\section{ABSTRACT}

Background and study aims Durable biliary drainage is essential during neoadjuvant therapy (NAT) in patients with pancreatic cancer who present with biliary obstruction. Plastic stents (PS) tend to occlude readily, resulting in delay/interruption of treatment. Our aim was to evaluate the safety and efficacy of self-expanding metal stents (SEMS) for biliary drainage in patients receiving NAT for pancreatic cancer.
Patients and methods From 2009 to 2014, all consecutive patients with resectable pancreatic cancer at one tertiary center had SEMS placed for biliary drainage before NAT was started. Data on biliary drainage efficacy, stent malfunction rates and procedural adverse events were collected.

Results One hundred forty-two consecutive patients with pancreatic cancer (mean age $66 \pm 9$ SD years; 81 male, $61 \mathrm{fe}$ male; 67 resectable, 75 borderline resectable) were enrolled. Eight-seven patients (61\%) had prior PS exchanged to SEMS and 55 (39\%) had SEMS placed upfront. Median duration from SEMS placement to the end of NAT/surgery was 111 days (range $44-282$ ). During NAT, SEMS malfunction requiring reintervention occurred in 16 patients $(11.2 \%)$ : tissue ingrowth 11 , stent occlusion from food 6 , stent migration 3, incomplete expansion 1, "tissue cheese-cutter" effect 1 , and cystic duct obstruction 1 . On subgroup analysis, no correlation between SEMS malfunction and stage of disease, prior PS, or duration of NAT was found $\left(r^{2}=0.05\right.$, $P=0.34)$. Presence of SEMS in situ did not affect pancreaticoduodenectomy.

Conclusion SEMS provide safe, effective and durable biliary drainage during NAT for pancreas cancer. Previously placed PS can be exchanged for SEMS. SEMS do not require removal prior to surgery.

Meeting presentations: Digestive Disease Week 2015 and 2017

with cancer of the pancreatic head frequently present with obstructive jaundice [6]. Preoperative biliary decompression may be unnecessary and can be harmful in patients undergoing early surgery [7]. On the other hand, in those receiving NAT, usually lasting for 4 to 6 months, durable biliary drainage is essential as these patients: 1 ) undergo delayed surgery; 2) many chemotherapy agents require near-normalization of liver function; and 3) immune suppression from NAT may predispose patients to cholangitis if adequate biliary drainage is not achieved, 
thereby resulting in interruptions in treatment, additional procedures, and increased morbidity.

Previous studies evaluating plastic biliary stents in the setting of NAT have shown that plastic stents tend to occlude within a few weeks. This necessitates additional endoscopic retrograde cholangiopancreatography (ERCP) prior to surgery [8]. Compared to a 10-French (3.3-mm diameter) plastic stent, the diameter of a self-expandable metal stent (SEMS) is 30 French (10 mm; equivalent to over nine $10-\mathrm{F}$ plastic stents in terms of circumference area). In a pilot study we showed that SEMS are safe and effective in achieving durable biliary drainage in patients with pancreatic cancer with biliary obstruction in the setting of NAT [9]. The aim of this study was to evaluate the safety and efficacy of SEMS during NAT in a larger cohort of patients with resectable and borderline resectable pancreatics cancer presenting with biliary obstruction.

\section{Patients and methods}

\section{Patient population}

This study was conducted at one tertiary care referral center where, since 2009, all patients with resectable or borderline resectable pancreatic cancer have received NAT and SEMS are placed in those presenting with biliary obstruction before starting NAT. From January 2009 to December 2014, all patients with resectable or borderline resectable pancreatic cancer were reviewed using a prospectively maintained database. Inclusion criteria included: 1) preoperative tissue-proven pancreatic adenocarcinoma (endoscopic ultrasonography-fine-need aspiration [EUS-FNA] or brushings); 2) cancer-related biliary obstruction; 3) resectable or borderline resectable lesion on imaging (EUS, computed tomography [CT], magnetic resonance imaging); 4) planned NAT; and 5) patient fit for planned pancreaticoduodenectomy at the time of stent placement. Exclusion criteria included: 1) no biliary obstruction; 2) indeterminate tissue diagnosis; 3) SEMS placed after initiation of NAT; 4) SEMS placement at an outside institution with treatment initiated prior to evaluation at our institution; and 5) patient not willing to receive NAT.

\section{Interventions}

All patients with bile duct obstruction suspected to be secondary to pancreatic cancer underwent a contrast-enhanced, triple phase, thin section, vascular reconstruction CT scan (pancreas protocol). These patients (including those with negative CT scan but a mass identified later on EUS) had laboratory testing, which included liver function tests, lipase, CA 19-9 (pre- and post-biliary decompression), hemoglobin, hematocrit and leukocyte count. In patients who had imaging scans done at outside institutions, based on the quality of the scan as reviewed by dedicated radiologists at the tertiary care center, a pancreas protocol scan was repeated if needed. The importance of obtaining a high-quality staging scan before doing any other invasive procedure (EUS-FNA and ERCP) was driven by the fact that these invasive procedures can cause pancreatitis and affect the specificity of the staging scan if done after the procedure. Resectable, borderline resectable, and locally advanced staging classification were as per previously described staging criteria [10].

If a tissue diagnosis was not already established prior to referral, EUS-FNA was performed. To obtain rapid and immediate cytopathology evaluation, a cytopathologist with a cytotechnician was present in the procedure room. If the on-site FNA was positive for adenocarcinoma, ERCP was performed for biliary SEMS placement while the patient was still sedated during the same session. The length of the SEMS was selected so as to leave enough healthy common hepatic duct above the proximal end of the stent to allow for subsequent surgical bilio-enteric anastomosis ("short metal stent"). On patients who previously underwent ERCP with plastic stent placement (usually at an outside hospital with no tissue diagnosis), EUS-FNA was performed and the plastic stent was removed and replaced with a SEMS if the on-site cytopathologist confirmed the diagnosis of adenocarcinoma. Procedure-related complications were recorded. SEMS from different companies can have variable characteristics (such as woven design versus laser-cut, foreshortening, variable radial force), so to prevent these variables from influencing the results, only one type of SEMS was used for all patients (Wallflex Biliary stent; Boston Scientific Inc, Nantucket, Massachusetts, United States).

All patients were discussed at our multidisciplinary pancreato-biliary conference (radiologists, surgeons, gastroenterologists, medical oncologists, radiation oncologists, cytopathologists, and geneticist) where tissue diagnosis and staging were confirmed, and based on the consensus of the group, NAT plan was determined.

Patients with resectable and borderline resectable pancreatic cancers were treated with NAT consisting of induction chemotherapy, chemoradiation or both. Those with resectable cancer were treated with preoperative chemoradiation and those with borderline resectable cancer were treated with chemotherapy initially. Restaging with CT scans was done 4 weeks after completion of therapy. Borderline resectable patients with tumor response (defined either as tumor size regression or stable tumor size and no evidence of metastasis, drop in CA 19-9 levels) were treated with chemoradiation following induction chemotherapy. Patients were again restaged with CT scan 4 weeks after completion of therapy prior to pancreaticoduodenectomy being considered. The NAT period was defined as the time from initiation of therapy until surgery or until evidence of disease progression noted on restaging scan (not candidate for surgery). During this period, patients were followed up at our multidisciplinary cancer center where physical examination, liver function tests, CA 19-9, blood counts and, imaging studies were done at regular intervals.

Because "short metal stents" were placed as described above, SEMS were not removed preoperatively. For those who underwent pancreaticoduodenectomy, their medical records were reviewed to assess if presence of SEMS at time of surgery affected surgical outcomes (technical difficulties encountered, duration of surgery, estimated blood loss, duration of hospital stay and complications). 


\section{Outcomes}

The primary outcome was to determine the efficacy of SEMS in durably relieving biliary obstruction. Efficacy in relieving biliary obstruction was evaluated by following-up liver function tests at established intervals (pre-procedure, within 1 week after SEMS placement and thereafter at 4- to 6-week intervals or as clinically indicated). SEMS durability in relieving biliary obstruction was determined by monitoring the efficacy of SEMS in relieving biliary obstruction during the entire NAT without the need for reintervention secondary to SEMS malfunction. Stentrelated malfunction (as against worsening disease) was defined as patients presenting with worsening jaundice, and/or cholangitis, and/or worsening liver functions tests, and/or worsening biliary dilation on imaging studies that reversed after endoscopic or interventional radiology reintervention. Evidence of stent occlusion was confirmed by cholangiogram during ERCP and by demonstrating improvement in liver function tests following stent intervention/replacement. Secondary outcomes included: 1) procedure-related complications (including but not limited to pancreatitis, bleeding, perforation, migration, cholangitis and cholecystitis); 2) the effect of prior plastic stent placement versus initial upfront SEMS placement on SEMS performance; 3) type of SEMS (covered versus uncovered); 4) cancer stage (resectable versus borderline resectable); 5) location of SEMS placement (placed at our institution versus an outside institution); 6) type of NAT received (induction chemotherapy versus chemoradiation versus both); and 7) effect of SEMS in situ on surgery outcomes.

\section{Institutional review board}

This study was approved by the local Institutional Board Review Committee. All patients gave informed and written consent for the procedures and entry into a prospectively maintained database.

\section{Statistics}

Statistical analysis was performed using Microsoft Excel (Microsoft Corporation, Redmond, Washington, United States) and GraphPad (GraphPad Software, Lajolla, California, United States). Continuous variables were summarized by using means and standard deviations for normally distributed variables and using medians and ranges for skewed distributions. Categorical variables were summarized by using proportions. Chi-square or Fisher exact tests were used to compare categorical variables. Continuous variables were compared using by using a $t$ test for normal data and a Mann-Whitney test and Kruskal-Wallis for skewed data. A P value $<0.05$ was used to determine statistical significance. All authors had access to the study data and reviewed and approved the final manuscript.

\section{Results}

During the study period (January 2009 to December 2014), 333 patients with resectable or borderline resectable pancreatic cancer were evaluated at our institution. Of these, 210 presented with biliary obstruction requiring intervention. The remain-

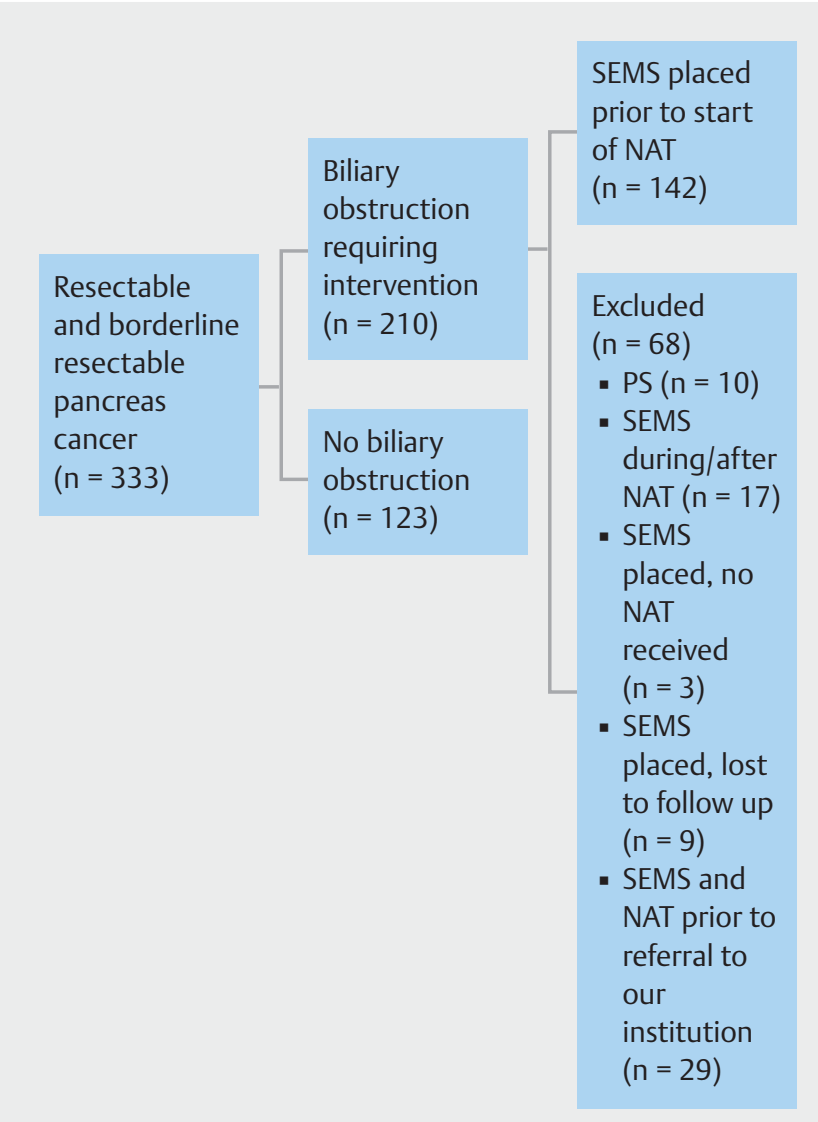

- Fig. 1 Flowchart of patients. SEMS, self-expanding metal stent (biliary); PS, plastic stent; NAT, neoadjuvant therapy.

ing 123 patients had pancreatic body and tail lesions or head/ uncinate process lesions without coexisting biliary obstruction. Of the 210 patients, 68 were excluded based on exclusion criteria ( $\triangleright$ Fig. 1), leaving a study population of 142 patients (81 male, 61 females; mean age $66 \pm 9$ SD years).

All these patients had SEMS placed for biliary obstruction and all underwent NAT after SEMS placement. Sixty-seven (47\%) of these patients were staged as resectable and $75(53 \%)$ as borderline resectable. Of the 142 patients, 87 (61\%) had undergone ERCP at an outside institution with placement of plastic biliary stents, with the majority of these being $10 \mathrm{~F}(3.3 \mathrm{~mm})$ in diameter. Majority of SEMS ( $n=124,87 \%$ ) were placed at the study institution. All SEMS were $10 \mathrm{~mm}$ in diameter and the lengths of the stents selected were either $4 \mathrm{~cm}$ or $6 \mathrm{~cm}$ so as to avoid stenting the common hepatic duct that will be subsequently required for bilio-enetric anastomosis. The 4-cm-long SEMS were placed in 33 patients with short $(1 \mathrm{~cm}$ to $1.5 \mathrm{~cm})$ bile duct strictures located behind the ampulla. The $6-\mathrm{cm}$ SEMS were placed in the rest of the patients or across the 4$\mathrm{cm}$-long SEMS when there was tissue in-growth occluding the 4-cm-long SEMS. The majority of the SEMS were uncovered ( $\mathrm{n}$ $=115,81 \%$; preferred at the study institution because removing the SEMS prior to surgery was not required). Liver function tests declined significantly following SEMS placement ( $\triangleright$ Table 1 ). 
- Table 1 Liver function tests and tumor markers pre- and post-SEMS placement.

\begin{tabular}{|l|c|c|c|}
\hline & Pre-SEMS placement & Post-SEMS placement & P value \\
\hline Bilirubin (mean, SD) & $10.1(7.6)$ & $1.6(1.5)$ & $<0.0001$ \\
\hline Alkaline phosphatase (mean, SD) & $496.4(249.6)$ & $173.5(74.7)$ & $<0.0001$ \\
\hline AST (mean, SD) & $190.27(128.5)$ & $45.9(55.2)$ & $<0.0001$ \\
\hline ALT (mean, SD) & $315.9(218.6)$ & $59.0(54.6)$ & $<0.0001$ \\
\hline CA 19-9 (mean, SD) & $1008.9(1442.8)$ & $970.3(1930.9)$ \\
\hline SEMS, self-expanding metal stent (biliary); SD, standard deviation; AST, aspartate aminotransferase; ALT, alanine aminotransferase.
\end{tabular}

Serum CA 19-9 showed no significant decline post-SEMS placement ( $\triangleright$ Table1).

All patients received NAT; 30 (21\%) were treated with induction chemotherapy, 57 (40\%) were treated with chemoradiation, and 55 (39\%) were treated with both induction chemotherapy and then chemoradiation. The median duration of the NAT was 85 days (range $32-261$ days) and the median duration from SEMS placement to the end point (pancreaticoduodenectomy or staging CT scan after completing NAT showing metastatic disease and hence patient now not a surgical candidate) was 110.5 days (range $44-282$ days; $>$ Fig. 2 ).

By 110.5 days (median duration), SEMS malfunction requiring reintervention occurred in $16(11.3 \%)$ patients and by 282 days (maximum duration) in 21 (14.8\%) patients ( $>$ Fig. 2 ): Tissue or tumor in-growth occurred in 11 patients, stent occlusion from debris or food in 6 , stent migration in 3 , incomplete expansion in 1, "tissue cheese-cutting" effect (as it happened very soon after placing stent) in 1 , and cystic duct obstruction (cholecystitis) in 1. The median duration from SEMS placement to SEMS malfunction in the 21 patients was 75 days (range $3-$ 216 days). ERCP-related complications occurred in 16 patients ( $11 \%$ ) consisting of mild pancreatitis in 6 , post-procedure pain

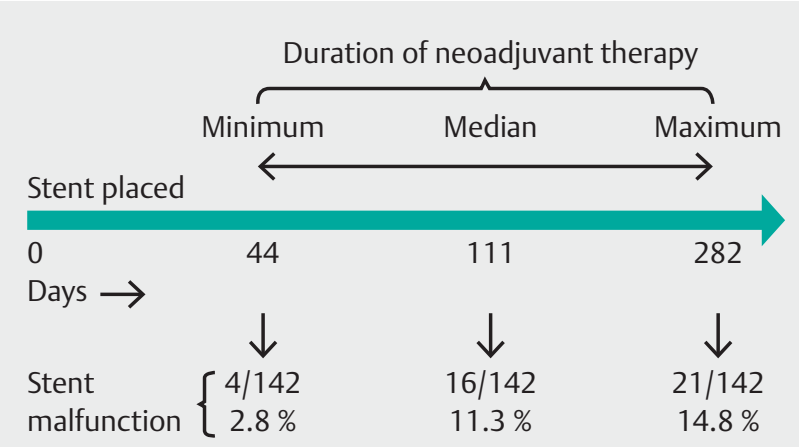

- Fig. 2 Self-expanding metal biliary stent (SEMS) malfunction requiring reintervention. Duration of neoadjuvant therapy was defined as days from stent placement to surgery or to stopping neoadjuvant therapy as patient declared non-surgical due to disease progressions. requiring hospital admission in 5 , bleeding in 2 , perforation in 1 , cholecystitis in 1 , and cholangitis in 1 .

On linear regression analysis, no significant correlation was found between the days to SEMS malfunction and the duration of NAT $\left(r^{2}=0.05, P=0.34\right)$ ( $\triangleright$ Fig. 3 ). Rates of stent malfunction and median days to SEMS-related reintervention were evaluated within subgroups which included: 1) those who received an initial plastic biliary stent versus upfront SEMS; 2) resectable versus borderline resectable disease; 3 ) placement of uncovered versus covered SEMS; 4) placement of SEMS at our institution versus placement of SEMS at an outside institution; and 5) type of NAT (induction chemotherapy, chemoradiation or both). No significant differences were found on subgroup analysis ( $\triangleright$ Table 2 ).

As per the operative notes and feedback from the surgeons, presence of a "short biliary stent" did not interfere with or pose any technical difficulties for surgery. Median estimated blood loss was $500 \mathrm{~mL}$ (range $50-3300 \mathrm{~mL}$ ). Median hospital stay was 10 days (range 6 to 43 days). No patient developed biliary leakage, strictures, or infection complications postoperatively.

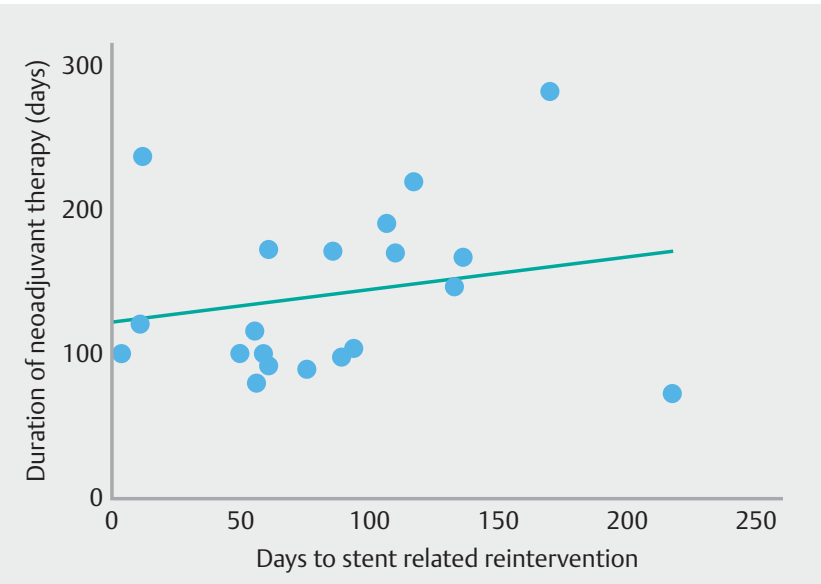

Fig. 3 Linear regression of days to stent malfunction requiring reintervention. 
- Table 2 Subgroup analysis.

\begin{tabular}{|c|c|c|c|c|c|c|}
\hline & Number & $\begin{array}{l}\text { SEMS-related } \\
\text { reinterventions } \\
(n, \%)\end{array}$ & $\begin{array}{l}\text { SEMS malfunction etiology } \\
\text { (n) }\end{array}$ & $P$ value & $\begin{array}{l}\text { Median days to SEMS- } \\
\text { related reintervention } \\
\text { (range) }\end{array}$ & $P$ value \\
\hline $\begin{array}{l}\text { Plastic stent } \\
\text { prior to SEMS }\end{array}$ & 87 & $10(11.5)$ & $\begin{array}{l}\text { Tissue ingrowth (6) } \\
\text { Debris/food in stent (3) } \\
\text { Migration (1) } \\
\text { Cheese cutting (1) }\end{array}$ & \multirow[t]{2}{*}{0.22} & $59(3-216)$ & \multirow[t]{2}{*}{0.35} \\
\hline Upfront SEMS & 55 & $11(20.0)$ & $\begin{array}{l}\text { Tissue ingrowth (5) } \\
\text { Debris food in stent (3) } \\
\text { Migration (2) } \\
\text { Inadequate stent expansion (1) } \\
\text { Cystic duct obstruction (1) }\end{array}$ & & $105(11-168)$ & \\
\hline $\begin{array}{l}\text { Resectable pan- } \\
\text { creatic cancer }\end{array}$ & 67 & $9(13.4)$ & $\begin{array}{l}\text { Tissue ingrowth (6) } \\
\text { Debris/food in stent (2) } \\
\text { Cystic duct obstruction (1) } \\
\text { Cheese cutting (1) }\end{array}$ & \multirow[t]{2}{*}{0.81} & $58(3-117)$ & \multirow[t]{2}{*}{0.12} \\
\hline $\begin{array}{l}\text { Borderline re- } \\
\text { sectable pan- } \\
\text { creatic cancer }\end{array}$ & 75 & $12(16.0)$ & $\begin{array}{l}\text { Tissue ingrowth (5) } \\
\text { Debris/food (4) } \\
\text { Stent migration (3) } \\
\text { Inadequate stent expansion (1) }\end{array}$ & & $95(8-216)$ & \\
\hline Uncovered SEMS & 116 & $16(13.8)$ & $\begin{array}{l}\text { Tissue ingrowth (11) } \\
\text { Debris/food in stent (4) } \\
\text { Inadequate stent expansion (1) } \\
\text { Cheese cutting (1) }\end{array}$ & \multirow[t]{2}{*}{0.54} & $68(3-216)$ & \multirow[t]{2}{*}{0.89} \\
\hline Covered SEMS & 26 & $5(19.2)$ & $\begin{array}{l}\text { Stent migration ( } 3 \text { ) } \\
\text { Debris/food in stent (2) } \\
\text { Cystic duct obstruction (1) }\end{array}$ & & $85(11-132)$ & \\
\hline $\begin{array}{l}\text { SEMS placed at } \\
\text { our institution }\end{array}$ & 124 & 17 (13.7) & $\begin{array}{l}\text { Tissue ingrowth (11) } \\
\text { Debris/food in stent (4) } \\
\text { Migration (1) } \\
\text { Cheese cutting (1) } \\
\text { Cystic duct obstruction (1) }\end{array}$ & \multirow[t]{2}{*}{0.31} & $73(3-216)$ & \multirow[t]{2}{*}{0.84} \\
\hline $\begin{array}{l}\text { SEMS placed at } \\
\text { outside institu- } \\
\text { tion }\end{array}$ & 18 & $4(22.2)$ & $\begin{array}{l}\text { Debris/food in stent ( } 2 \text { ) } \\
\text { Migration ( } 2 \text { ) } \\
\text { Inadequate stent expansion (1) }\end{array}$ & & $80(11-132)$ & \\
\hline Chemo alone & 30 & $7(23.3)$ & $\begin{array}{l}\text { Tissue ingrowth (4) } \\
\text { Debris/food in stent (2) } \\
\text { Cystic duct obstruction (1) }\end{array}$ & \multirow[t]{3}{*}{0.18} & $56(10-216)$ & \multirow[t]{3}{*}{0.12} \\
\hline $\begin{array}{l}\text { Chemo- } \\
\text { radiation }\end{array}$ & 57 & $5(8.8)$ & $\begin{array}{l}\text { Tissue ingrowth ( } 3 \text { ) } \\
\text { Debris/food in stent ( } 2 \text { ) } \\
\text { Cheese cutting (1) }\end{array}$ & & $75(3-92)$ & \\
\hline $\begin{array}{l}\text { Chemo + chemo- } \\
\text { radiation }\end{array}$ & 55 & $9(16.4)$ & $\begin{array}{l}\text { Tissue ingrowth (4) } \\
\text { Stent migration (3) } \\
\text { Debris/food in stent (2) } \\
\text { Inadequate stent expansion (1) }\end{array}$ & & $107(11-168)$ & \\
\hline
\end{tabular}

\section{Discussion}

In 2016, an estimated that 53,070 new cases of pancreatic cancer were diagnosed in the United States and 41,780 of these patients will die from the disease [11]. More than $70 \%$ of patients with cancer located in the pancreatic head develop obstructive jaundice [6]. Surgical resection is the only hope for cure. Biliary drainage may not be necessary in those undergoing early surgery as risk of bacterial cholangitis is rare with ma- lignant biliary obstruction, provided the bile duct hasn't been instrumented. Previous studies have shown no advantage to preoperative biliary drainage in those being considered for early surgery. In fact, some have even shown a significantly higher rate of complications in the perioperative period in those who underwent biliary drainage in the early surgery group [7, 12].

Adjuvant therapy for pancreatic cancer following surgery has shown survival benefits; however several patients may not receive adjuvant therapy in a timely manner due to complica- 
tions or declining performance status following surgery [13, 14]. In the 30-year Mayo experience, only $60 \%$ of patients went on to receive adjuvant therapy following surgery [13]. NAT, on the other hand, can be given to the majority of patients up front and is an accepted approach for patients with borderline resectable pancreatic cancer. Increasing numbers of patients with resectable pancreatic cancer are now also receiving NAT $[1,5,15-19]$. Induction chemotherapy and chemoradiation therapy prior to surgery may target and treat micrometastatic disease, increase the potential for negative surgical margins (R0) and identify patients unlikely to gain a survival benefit due to rapidly progressive or unrecognized metastatic disease $[5,20]$. Results from our pancreaticobiliary group have shown significant survival benefits using NAT in patients with resectable and borderline resectable pancreas cancer [1].

With a neoadjuvant approach, surgery is delayed many months and hence there is a need for effective and durable biliary drainage, particularly driven by the fact that many chemotherapy agents require adequate liver function. Moreover, immune suppression with NAT can predispose patients to risks of cholangitis. Because many centers either do not have an EUSFNA service or have no on-site cytopathologist available, several patients presenting with pancreas head mass and biliary obstruction undergo ERCP with brushings and placement of plastic stents. In the current study, there were over $60 \%$ of patients presenting in a similar manner with a plastic stent from outside the hospital. During NAT, plastic stents tend to occlude readily, necessitating additional ERCPs and often delaying or interrupting treatment [8]. Boulet et al showed that with placement of $10 \mathrm{~F}$ plastic stents, $59 \%$ of patients $(27 / 49)$ receiving NAT had to undergo unplanned ERCP due to worsening liver function tests or cholangitis, with the interruption of therapy in $13 \mathrm{pa}$ tients for a median of 8 days [8].

SEMS provide more durable biliary drainage compared to plastic stents in palliation of advanced malignant biliary obstruction ( $17 \%$ stent dysfunction rate versus $40 \%$, respectively) [21]. In respect to the area of circumference $\left(\pi \times r^{2}\right)$, a $10-\mathrm{mm}$ diameter SEMS is equal to more than nine plastic stents, each with a 3.3-mm (10 French) diameter. However, SEMSs are significantly more expensive than plastic stents. Despite their higher cost upfront, SEMs have been shown to be more cost-effective than plastic stents as their higher patency rates reduce the need for subsequent ERCPS, especially if the patient has a longer life expectancy [21]. Their safety and efficacy, however, in the setting of NAT is not well established. Similarly, the impact of a SEMS lying in situ on the technical difficulties, if any, in performing pancreaticoduodenectomy is not well studied. Until recently, SEMS were not approved by the Food and Drug Administration for use in patients with pancreatic cancer where there were intentions for surgical resection, for fear of SEMS-induced difficulties during surgery. Hence the primary reason to do this study was to evaluate the safety and efficacy of SEMS during NAT for pancreatic cancer and to determine if they posed any difficulties during surgery. In view of the high rate of complications (frequent occlusion, interruption of therapy, mortality) associated with plastic stents used during NAT as de- scribed above, we did not find it ethical to use plastic stents for biliary drainage during NAT as a control arm.

Numerous small studies, including one from this center, have shown SEMS to be safe and effective for biliary drainage during NAT. Mullen et al observed $45 \%$ of patients (75/166) with plastic stents placed during NAT experienced complications, compared to $7 \%(2 / 29)$ with SEMS [22]. Wasan et al showed a $93 \%$ rate of cholangitis or cholestasis in patients with plastic stents $(39 / 42)$ and $15 \%$ in patients with SEMS (2/ 13) [23]. Adams et al found the rate of complications with plastic stents to be $20 \%$ per month in place $(n=43)$ versus $3 \%$ per month for SEMS $(n=9)$ [24]. We have previously shown in a prospective non-randomized study $(n=55)$ a SEMS dysfunction rate of $12 \%$ during NAT [9].

In the current study, we report our experience in a much larger cohort of 142 patients with the efficacy and safety of biliary drainage using SEMS during NAT. Similar to previous studies, SEMS were highly effective in achieving biliary drainage as was evidenced by significant improvement in liver function. This improvement was durable without the need for reintervention in the majority of patients throughout the treatment period until surgery or to the end of NAT if follow-up scan showed metastatic disease (median duration of treatment 110.5 days).

During the treatment period (median 110.5 days), SEMS malfunction requiring reintervention was observed in $11.3 \%$ of patients which is similar to the $12 \%$ reported earlier in a cohort of 55 patients [9]. In some patients, NAT-to-surgery duration extended up to 282 days, and overall, stent malfunction requiring reintervention occurred in fewer than $15 \%$ of patients. Hence, SEMS provided durable biliary drainage in $85 \%$ to $88 \%$ of patients during the treatment period. Thus, the overwhelming majority of patients had no interruptions in therapy for stent-related issues or biliary obstruction.

In patients in whom SEMS malfunctioned, we were unable to identify any factor that could correlate with the likelihood of that event. Conceptually speaking, the longer the SEMS is in place, the higher the likelihood of it eventually malfunctioning. However, within the range of SEMS placement to surgery/endof-NAT in this study (44-282 days), no correlation between the duration of SEMS in situ to SEMS malfunction was observed. We also investigated the influence of prior ERCP with plastic biliary stent exchanged to SEMS versus ERCP with up front SEMS on the rate of SEMS malfunction. In this study, $61 \%$ of patients had prior plastic stents. Despite the fact that approximately $61 \%$ of patients referred to us had plastic stents placed at outside hospitals, bilirubin levels were high in many patients, as several presented with plastic stent occlusion or were referred to us within 24 hours after plastic stent placement. Presence of a prior plastic stent exchanged to SEMS showed no difference compared to upfront SEMS when looking at SEMS malfunction rate. Similarly, there was also no difference in the malfunction rate when comparing cancer stage (resectable versus borderline resectable), type of SEMS (covered versus uncovered), modality of NAT used (chemotherapy, chemoradiation or both), and whether the SEMS was placed at our tertiary institution or the referring institution. Procedure-related complica- 
tion rates (EUS-FNA and ERCP) were within the acceptable range and there was no stent-related mortality.

As per our protocol, SEMS were not removed before surgery. We selected the length of SEMS so as to allow for enough normal bile duct above the proximal end of the SEMS for subsequent bilio-enteric anastomosis. Hence the shortest possible length of the SEMS required to bridge the obstruction was used. Because foreshortening, woven-design SEMS were used, we were cognizant of the fact that if a stent did not fully expand, the deployed length of it might turn out to be longer than the stated length of a fully-expanded SEMS. To address that issue, after advancing the constrained stent delivery system into the bile duct, we initially deployed the proximal end of the stent for about $1 \mathrm{~cm}$, then pulled the delivery system down so as to not cover $1 \mathrm{~cm}$ to $2 \mathrm{~cm}$ of the common hepatic duct (needed for subsequent bilio-enteric anastomosis), and then deployed the rest of the stent. With that approach, it was not necessary to remove the SEMS prior to surgery. Presence of a SEMS in situ during surgery did not add any major technical difficulties during pancreaticoduodenectomy, although this aspect of the study was based on subjective input from the four surgeons who did all the surgeries on patients included in the study. On objective analysis, estimated blood loss, duration of hospital stay and postoperative complications were similar to historical controls in patients without SEMS [22].

Limitations of our study include its retrospective review from a prospectively collected database as well as a lack of a control group of patients with plastic stents for biliary drainage. However, with the prohibitively high rate of complications with plastic stents during NAT as shown in other studies, the protocol at our center is to place SEMS in essentially all patients. The practice of doing EUS-FNA with on-site cytopathology read and then ERCP with SEMS all as one procedure may not be universally applicable. Although we would prefer that these patients be sent to centers with the above expertise, we anticipate that the practice of ERCP with plastic stent in patients with a pancreatic head mass and biliary obstruction will continue despite the fact that these patients rarely develop cholangitis. The lack of any predictive factor correlating with SEMS malfunction could be due to the low number of patients with stent malfunction in relation to the multiple variables looked at. Last, but not least, SEMS are prohibitively expensive in relation to earnings for many people in third-world countries. In that regard, investigating the efficacy of SEMS versus using multiple 10F plastic stents for biliary drainage during NAT may be considered.

\section{Conclusion}

In summary, to our knowledge, we report on the largest cohort of patients using SEMS for biliary drainage in patients undergoing NAT for resectable and borderline resectable pancreatic cancer. SEMS for biliary drainage in these patients have a good safety profile and provide effective and durable biliary drainage, thus limiting interruptions or delays in therapy. SEMS do not need to be removed prior to pancreaticoduodenectomy as long as an appropriate length of SEMS is selected so as to allow for enough normal bile duct above the proximal margin of the
SEMS for subsequent bilio-enteric anastomosis. If plastic stents have initially been placed, they can be exchanged to SEMS if patients are to undergo NAT without affecting the performance of the SEMS.

\section{Competing interests}

None

References

[1] Christians KK, Heimler JW, George B et al. Survival of patients with resectable pancreatic cancer who received neoadjuvant therapy. Surgery 2016; 159: $893-900$

[2] Rashid OM, Pimiento JM, Gamenthaler AW et al. Outcomes of a clinical pathway for borderline resectable pancreatic cancer. Ann Surg Oncol 2016; 23: 1371 - 1379

[3] Mellon EA, Hoffe SE, Springett GM et al. Long-term outcomes of induction chemotherapy and neoadjuvant stereotactic body radiotherapy for borderline resectable and locally advanced pancreatic adenocarcinoma. Acta Oncol 2015; 54: 979-985

[4] Tang K, Lu W, Qin W et al. Neoadjuvant therapy for patients with borderline resectable pancreatic cancer: A systematic review and meta-analysis of response and resection percentages. Pancreatology 2016; $16: 28-37$

[5] Fathi A, Christians KK, George B et al. Neoadjuvant therapy for localized pancreatic cancer: guiding principles. J Gastrointest Oncol 2015; 6: $418-429$

[6] Porta M, Fabregat X, Malats $\mathrm{N}$ et al. Exocrine pancreatic cancer: symptoms at presentation and their relation to tumour site and stage. Clin Transl Oncol 2005; 7: 189-197

[7] van der Gaag NA, Rauws EA, van Eijck CH et al. Preoperative biliary drainage for cancer of the head of the pancreas. N Engl J Med 2010; 362: $129-137$

[8] Boulay BR, Gardner TB, Gordon SR. Occlusion rate and complications of plastic biliary stent placement in patients undergoing neoadjuvant chemoradiotherapy for pancreatic cancer with malignant biliary obstruction. J Clin Gastroenterol 2010; 44: 452-455

[9] Aadam AA, Evans DB, Khan A et al. Efficacy and safety of self-expandable metal stents for biliary decompression in patients receiving neoadjuvant therapy for pancreatic cancer: a prospective study. Gastrointest Endosc 2012; 76: 67-75

[10] Wolff RA, Varadhachary GR, Evans DB. Adjuvant therapy for adenocarcinoma of the pancreas: analysis of reported trials and recommendations for future progress. Ann Surg Oncol 2008; 15: 2773 2786

[11] Siegel RL, Miller KD, Jemal A. Cancer statistics, 2016. CA Cancer J Clin 2016; 66: 7-30

[12] Morris-Stiff G, Tamijmarane A, Tan YM et al. Pre-operative stenting is associated with a higher prevalence of post-operative complications following pancreatoduodenectomy. Int J Surg 2011; 9: 145-149

[13] Corsini MM, Miller RC, Haddock MG et al. Adjuvant radiotherapy and chemotherapy for pancreatic carcinoma: the Mayo Clinic experience (1975-2005). J Clin Oncol 2008; 26: 3511-3516

[14] Yeo C], Abrams RA, Grochow LB et al. Pancreaticoduodenectomy for pancreatic adenocarcinoma: postoperative adjuvant chemoradiation improves survival. A prospective, single-institution experience. Ann Surg 1997; 225: 621-633; discussion 633-626

[15] Bergquist JR, Puig CA, Shubert CR et al. Carbohydrate antigen 19-9 elevation in anatomically resectable, early-stage pancreatic cancer is 
independently associated with decreased overall survival and an indication for neoadjuvant therapy: a national cancer database study. J Am Coll Surg 2016; 223: $52-65$

[16] lelpo B, Duran H, Diaz E et al. Preoperative treatment with gemcitabine plus nab-paclitaxel is a safe and effective chemotherapy for pancreatic adenocarcinoma. Eur J Surg Oncol 2016; 42: 1394 - 1400

[17] Casadei R, Di Marco M, Ricci C et al. Neoadjuvant chemoradiotherapy and surgery versus surgery alone in resectable pancreatic cancer: a single-center prospective, randomized, controlled trial which failed to achieve accrual targets. J Gastrointest Surg 2015; 19: 1802 - 1812

[18] Golcher H, Brunner TB, Witzigmann $\mathrm{H}$ et al. Neoadjuvant chemoradiation therapy with gemcitabine/cisplatin and surgery versus immediate surgery in resectable pancreatic cancer: results of the first prospective randomized phase II trial. Strahlenther Onkol 2015; 191: $7-16$

[19] Varadhachary GR, Wolff RA, Crane $\mathrm{CH}$ et al. Preoperative gemcitabine and cisplatin followed by gemcitabine-based chemoradiation for resectable adenocarcinoma of the pancreatic head. J Clin Oncol 2008; 26: $3487-3495$
[20] Spitz FR, Abbruzzese JL, Lee JE et al. Preoperative and postoperative chemoradiation strategies in patients treated with pancreaticoduodenectomy for adenocarcinoma of the pancreas. J Clin Oncol 1997; 15: $928-937$

[21] Walter D, van Boeckel PG, Groenen MJ et al. Cost Efficacy of metal stents for palliation of extrahepatic bile duct obstruction in a randomized controlled trial. Gastroenterology 2015; 149: 130-138

[22] Mullen JT, Lee JH, Gomez HF et al. Pancreaticoduodenectomy after placement of endobiliary metal stents. J Gastrointest Surg 2005; 9: 1094- 1104 ; discussion 1104-1095

[23] Wasan SM, Ross WA, Staerkel GA et al. Use of expandable metallic biliary stents in resectable pancreatic cancer. Am J Gastroenterol 2005; 100: $2056-2061$

[24] Adams MA, Anderson MA, Myles JD et al. Self-expanding metal stents (SEMS) provide superior outcomes compared to plastic stents for pancreatic cancer patients undergoing neoadjuvant therapy. J Gastrointest Oncol 2012; 3: 309-313 